\title{
Effect of Lipid Extracted from Tsao-ko (Amomum tsao-ko Crevost et Lemaire) on Digestive Enzyme Activity, Antioxidant Activity, Plasma and Liver Lipids, and Blood Glucose Levels of Mice
}

\author{
Longquan $\mathrm{YU}^{1,2}$, Nobuya SHIRAI ${ }^{3, *}$, Hiramitsu SuzUKI ${ }^{3,4}$, Tsuyoshi HosonO ${ }^{5}$, \\ Yoshijiro NAKAJIMA ${ }^{6}$, Masahiro KAJIWARA ${ }^{7}$ and Kazuhiro TAKATORI ${ }^{7}$ \\ ${ }^{1}$ United Graduate School of Agricultural Science, Tokyo University of Agriculture and Technology, 3-5-8, \\ Saiwai, Fuchu, Tokyo 183-8509, Japan \\ ${ }^{2}$ College Chemical Engineering Shijiazhuang University, No. 6 Changjiang Road, Shijiazhuang High and New \\ Technology Development Zone, Shijiazhuang, Hebei, Province, China \\ ${ }^{3}$ National Food Research Institute, 2-1-12, Kannondai, Tsukuba, Ibaraki 305-8642, Japan \\ ${ }^{4}$ Kagawa Nutrition University, 3-9-21, Chiyoda, Sakado, Saitama 350-0288, Japan \\ ${ }^{5}$ Ohta's Isan Inc., 2-3-2, Sengoku, Bunkyo-ku, Tokyo 112-0011, Japan \\ ${ }^{6}$ Ohta's Isan Inc., 957, Shishiko, Ushiku, Ibaraki 300-1231, Japan \\ ${ }^{7}$ Meiji Pharmaceutical University, 2-522-1, Noshio, Kiyose, Tokyo 204-8588, Japan
}

(Received March 21, 2008)

\begin{abstract}
Summary Lipids extracted from tsao-ko were separated into three fractions with silica gel column chromatography and fed to mice ( 3 mo old) for $90 \mathrm{~d}$ to clarify their inhibitory activity on digestive enzyme activity. The diets contained the following: control-no tsao-ko, $0.05 \%$ total lipid of tsao-ko (TL), $0.0109 \%$ chloroform fraction (CF), $0.0245 \%$ acetone fraction $(\mathrm{AF})$, or $0.00365 \%$ methanol fraction $(\mathrm{MeF})$. Although CF and AF slightly inhibited the activities of $\alpha$-glucosidase, $\alpha$-amylase, and lipase, intakes of these fractions had little influence on plasma and liver lipid concentrations when compared with the control diet. MeF did not inhibit $\alpha$-glucosidase but had DPPH radical scavenging activity and the mice fed this fraction had the most marked reduction in plasma glucose and TBARS concentrations compared with the other diet groups. These results suggest that the fat-soluble polar components of tsao-ko contain an active component that might be associated with decreased plasma glucose and TBARS concentrations in mice.
\end{abstract}

Key Words tsao-ko, lipids, DPPH, inhibitory activity, glucose

Spices have been utilized in numerous ways throughout history and are amongst the thousands of food flavoring substances used worldwide (1-3). Dietary spices are non-toxic and studies in animal models have suggested that they could be beneficial to human health (3-9). Additionally, in China, many spices have been used in folk medicine. Amomum tsao-ko Crevost et Lemaire (tsao-ko), which belongs to the Zingiberaceae family, is used in Chinese cuisine and in traditional and folk medicine for treating stomach disorders and throat infections. In an earlier screening experiment, we demonstrated that $1 \%$ tsao-ko can lower triacylglycerol (TG) levels ( $72.5 \%$ of control) and has hypoglycemic $(66.2 \%)$ and antioxidant activity $(71.1 \%)$ in mice (9) but the active components of tsao-ko associated with these effects were not identified.

A number of studies have indicated that the oils from

\footnotetext{
*To whom correspondence should be addressed.

E-mail: nshinya@affrc.go.jp

Abbreviations: AF, acetone fraction; $\mathrm{CF}$, chloroform fraction; DMSO, dimethyl sulfoxide; DPPH, 2,2-diphenyl-1-picrylhydrazyl; Glu, glucose; MeF, methanol fraction; PL, phospholipids; TBARS, thiobarbituric acid reactive substances; T-chol, total cholesterol; TG, triacylglycerol; TL, total lipids.
}

spices have beneficial effects on human health (10-12). For example, garlic oil has been shown to inhibit oxidative damage and bone loss (12-14). It was thought possible that the effective components of tsao-ko might also be contained in a lipid fraction. We previously reported the separation of spice lipids into three fractions, namely, a chloroform eluted fraction (containing TG), an acetone eluted fraction (containing glycolipids), and a methanol eluted fraction (containing phospholipids) using a silica gel column (15). In the present study we separated the lipids of tsao-ko into these three fractions to determine which fraction was most effective in reducing plasma lipids and glucose, and liver lipids in mice.

\section{MATERIALS AND METHODS}

Materials. Chloroform, acetone, and methanol were obtained from Wako Pure Chemical Industries, Ltd. (Osaka, Japan) and were used without further purification. Anhydrous sodium sulfate $\left(\mathrm{Na}_{2} \mathrm{SO}_{4}\right)$ and silica gel (C-300; 45-75 mm, for silica gel column chromatography) were also purchased from Wako Pure Chemical Industries, Ltd. The dried fruits of tsao-ko were purchased at the Liouzhou herbal market, Guangxi, China, in March 2004. After peeling the skin of dried tsao-ko 
fruits, they were reduced to a powder using a disintegrator (Ultra Centrifugal Mill, MRK Co., Ltd., Tokyo, Japan) at room temperature. Lard was supplied by NOF Co., Ltd., Tokyo, Japan. Salt and vitamin mixtures were purchased from Oriental Yeast Co., Ltd., Tokyo, Japan. The $\alpha$-glucosidase was purchased from Oriental Yeast Co., Ltd. and 2,2-diphenyl-1-picrylhydrazyl (DPPH), $\alpha$ amylase and lipase were purchased from Sigma (MO, USA).

Extraction and fractionation. The total lipids of tsaoko were extracted from the powders of tsao-ko by the method of Bligh and Dyer (16). Silica gel chromatography was performed according to the method of Suzuki et al. (15). The total lipid (TL) extract of tsao-ko was applied to a column $(25 \times 300 \mathrm{~mm})$ packed with silica gel in chloroform. The chloroform fraction (CF) was removed by elution with $600 \mathrm{~mL}$ of chloroform, followed by the acetone fraction (AF) with $500 \mathrm{~mL}$ of acetone and then the methanol fraction (MeF) with $600 \mathrm{~mL}$ of methanol. After the solvents were reduced by evaporation, each fraction was weighed.

Inhibitory activities of $\alpha$-glucosidase, $\alpha$-amylase, and lipase. The various lipid fractions were dissolved in dimethyl sulfoxide (DMSO). The inhibitory activity of $\alpha$ glucosidase was assayed by method of Tadera et al. (17). The $\alpha$-amylase inhibitory activity was measured using a Wako-amylase kit (Wako Pure Chemical Industries, Ltd.). The lipase inhibitory activity was measured using a modification of the method of Han et al. (18). A mixture of triolein $(80 \mathrm{mg})$, phosphatidylcholine $(10 \mathrm{mg})$, bile salt $(5 \mathrm{mg})$, and $1 \%$ albumin in $9 \mathrm{~mL}$ of $0.1 \mathrm{M}$ Tris buffer ( $\mathrm{pH}$ 7.0) was homogenized with a physcotron (NS-50, Microtec Co., Ltd., Chiba, Japan). This mixture (100 $\mu \mathrm{L}$ ) was incubated with $0.05 \mathrm{~mL}$ (2 units) of pancreatic lipase solution and $10 \mu \mathrm{L}$ of various concentrations of sample solutions for $30 \mathrm{~min}$ at $37^{\circ} \mathrm{C}$. The fatty acid released from triolein was measured by the Wako non-esterified fatty acid-C (NEFA-C) test kit (Wako Pure Chemical Industries, Ltd.). All experiments were performed 4-6 times.

Determination of radical-scavenging activity. The DPPH radical scavenging activity of each lipid fraction was assayed by a modification of Bloiss' method (19). Samples of lipid fractions $(0.5-15 \mathrm{~g} / \mathrm{L})$ in DMSO $(10 \mu \mathrm{L})$ were placed in wells of a micro-plate. Twenty micromole DPPH isopropanol solution $(200 \mu \mathrm{L})$ was added to each well and the absorbance was measured at $550 \mathrm{~nm}$ after 5 min. The $\mathrm{IC}_{50}$ of each lipid fraction was estimated from the linearity point. This experiment was performed 3 times.

Diets. The composition of the control diet was as follows: $47.8 \%$ cornstarch, $20 \%$ casein, $15 \%$ sucrose, $6 \%$ lard, $5 \%$ cellulose powder, $4 \%$ salt mixture, $2 \%$ vitamin mixture and $0.2 \%$ L-methionine. The salt mixture contained per $100 \mathrm{~g}$ : $\mathrm{CaHPO}_{4} \cdot 2 \mathrm{H}_{2} \mathrm{O}, 14.56 \mathrm{~g} ; \mathrm{KH}_{2} \mathrm{PO}_{4}$, $25.72 \mathrm{~g} ; \mathrm{NaH}_{2} \mathrm{PO}_{4}, 9.35 \mathrm{~g} ; \mathrm{NaCl}, 4.66 \mathrm{~g}$; Ca-lactate, 35.09; Fe-citrate, $3.18 \mathrm{~g} ; \mathrm{MgSO}_{4}, 7.17 \mathrm{~g} ; \mathrm{ZnCO}_{3}$, $0.11 \mathrm{~g} ; \mathrm{MnSO}_{4} \cdot 4 \sim 5 \mathrm{H}_{2} \mathrm{O}, 0.12 \mathrm{~g} ; \mathrm{CuSO}_{4} \cdot 5 \mathrm{H}_{2} \mathrm{O}, 0.03 \mathrm{~g}$; $\mathrm{KI}, 0.01 \mathrm{~g}$. The vitamin mixture contained per $100 \mathrm{~g}$ : vitamin $\mathrm{A}$-acetate, $0.1 \mathrm{~g}$; vitamin $\mathrm{D}_{3}, 0.25 \mathrm{mg}$; vitamin
$\mathrm{E} \cdot$ acetate, $0.5 \mathrm{~g}$; vitamin $\mathrm{K}_{3}, 0.52 \mathrm{~g}$; vitamin $\mathrm{B}_{1} \cdot \mathrm{HCl}$, $0.12 \mathrm{~g}$; vitamin $\mathrm{B}_{2}, 0.4 \mathrm{~g}$; vitamin $\mathrm{B}_{6} \cdot \mathrm{HCl}, 0.08 \mathrm{~g}$; vitamin $\mathrm{B}_{12}, 0.05 \mathrm{mg}$, vitamin $\mathrm{C}$, $3.0 \mathrm{~g}$; D-biotin, $2.0 \mathrm{mg}$; folic acid, $0.02 \mathrm{~g}$; calcium pantothenate, $0.5 \mathrm{~g}$; p-aminobenzoic acid, $0.5 \mathrm{~g}$; niacin, $0.6 \mathrm{~g}$; inositol, $0.6 \mathrm{~g}$; choline chloride, $20 \mathrm{~g}$; cellulose powder, $73.1 \mathrm{~g}$. The four experimental diets contained $0.05 \%$ total lipid (TL) of tsao-ko, or $0.0109 \% \mathrm{CF}$, or $0.0245 \% \mathrm{AF}$, or $0.00365 \%$ MeF instead of cornstarch. The amount of each lipid fraction added was equivalent to the experimental diet which contained 1\% of tsao-ko powder (9). The control and experimental diets were made once a month, and stored below $5^{\circ} \mathrm{C}$.

Animals. Male mice, of the Crlj: CD-1 (ICR) strain (4 wk old), were obtained from Charles River Japan, Inc. (Atsugi, Kanagawa, Japan). All animals were switched from a laboratory chow, MF (Oriental Yeast Co., Ltd.) to the control and experimental diets at $12 \mathrm{wk}$ of age. Mice were randomly divided into five groups of eight animals each and each group was fed on the control or an experimental diet for $90 \mathrm{~d}$. Animals had free access to the experimental or control diets until they were fasted and water until they were killed. Body weights were measured once a month. The animals were housed in suspended stainless-steel cages with wire mesh bottoms. The animal room was kept at $24 \pm 0.5^{\circ} \mathrm{C}$ and the relative humidity at $65 \pm 5 \%$. Room lighting consisted of $12-\mathrm{h}$ periods of light and dark. All mice were maintained according to the guidelines for experimental animals of the National Agriculture Food Research Organization, Japan.

Preparation of plasma, liver homogenates, and whole body samples. At the end of the feeding trials, all mice were fasted for $20 \mathrm{~h}$ before being anesthetized with diethyl ether. Blood was then collected from the inferior vena cava with a heparinized syringe and placed in icecold tubes. The plasma was separated by centrifugation at $900 \times g$ for $20 \mathrm{~min}$ at $4^{\circ} \mathrm{C}$. After collecting the blood, the livers were removed without perfusion and homogenized with 9 volumes of $1 / 15 \mathrm{~mol} / \mathrm{L}$ phosphate-buffered saline ( $\mathrm{pH}$ 7.4) using a Teflon-glass homogenizer. The mouse body was crushed under liquid nitrogen to extract the total lipids by the method of Bligh and Dyer (16). Plasma samples, liver homogenates, and mouse body samples were stored at $-30^{\circ} \mathrm{C}$ until required for lipid, glucose and body fat analyses.

Plasma glucose, lipids and thiobarbituric acid reactive substances, liver lipids and body fat analyses. Total cholesterol (T-chol), TG and phospholipids (PL) in plasma and liver, and glucose (Glu) in plasma were determined by Wako commercial analytical kits (Wako Pure Chemical Industries, Ltd.). Plasma concentrations of thiobarbituric acid reactive substances (TBARS) were measured by the method of Yagi (20). The lipid contents of the whole body were determined using the method described by Bligh and Dyer (16).

Statistical analyses. All results were expressed as mean \pm SE. The statistical significance of differences in lipid components and glucose between the experimental tsao-ko fraction groups were determined by one-way 
analysis of variance (ANOVA) and Spjotvoll/Soline test using the STATISTICA statistical program package (Stat-Soft Inc., Oklahoma, USA); the significance was set at $p<0.05$.

\section{RESULTS}

\section{Lipid yield from tsao-ko fractions}

The total lipid concentration of tsao-ko powders was $51.2 \mathrm{mg} / \mathrm{g}$. Following fractionation of the total lipid the acetone soluble fraction had the highest yield (approximately $48 \%$ ), followed by the chloroform fraction (approximately 21\%) and then the methanol fraction (approximately $7 \%$ ).

Inhibitory activities of $\alpha$-glucosidase, $\alpha$-amylase, and lipase and DPPH radical-scavenging activity

The inhibitory activities of each lipid fraction on $\alpha$ glucosidase, $\alpha$-amylase, and lipase are presented in Fig. 1. $\alpha$-Glucosidase activity was suppressed by $\mathrm{CF}$ and AF. The greatest inhibition was observed with the AF followed by the CF. In contrast, MeF showed a tendency to enhance the $\alpha$-glucosidase activity with increasing con-
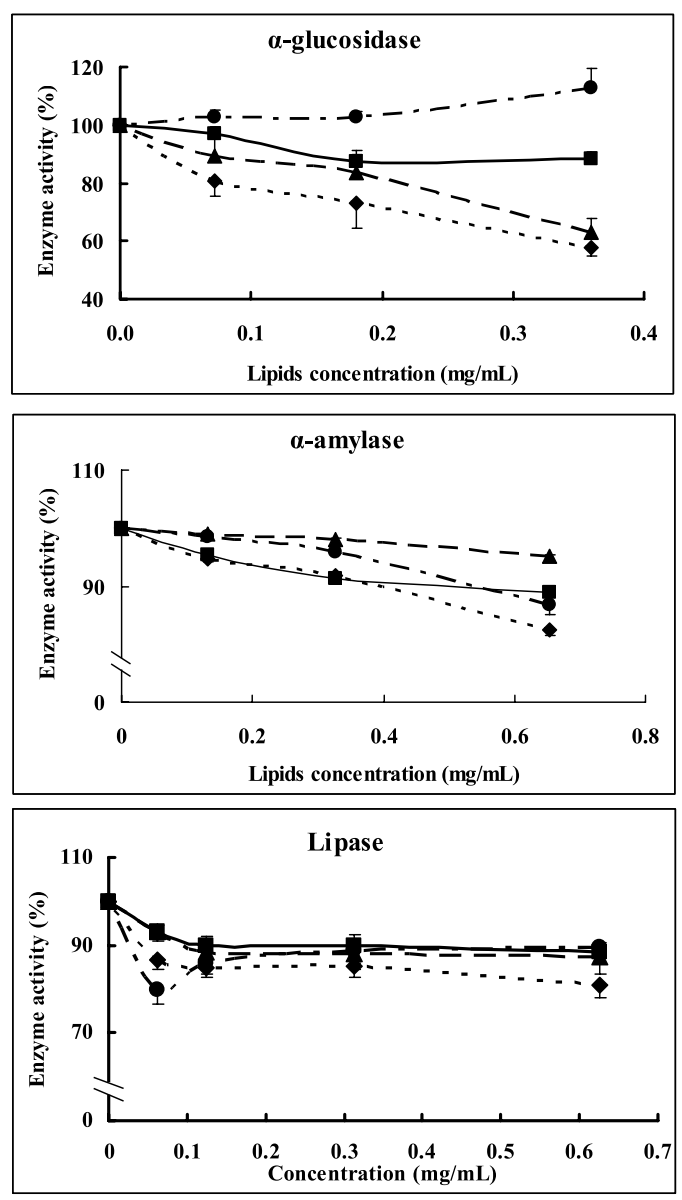

$\longrightarrow-T L--\star--C F \cdots \cdots \cdot \cdots \cdot A F-\cdot \bullet-\cdot M e F$

Fig. 1. Effect of total lipids and each lipid fraction from tsao-ko on $\alpha$-glucosidase, $\alpha$-amylase, and lipase activities in vitro. Results are expressed as means. TL, total lipid of tsao-ko; CF, chloroform fraction; AF, acetone fraction; MeF, methanol fraction. centrations. The inhibitory action of each lipid fraction on $\alpha$-amylase activity was less pronounced than that on $\alpha$-glucosidase activity. For lipase activity, these lipid fractions showed hardly any inhibition. However, a slight inhibition of lipase by MeF was found at the low lipid concentration but it declined, at the higher concentrations, to a level similar to that seen for TL. The DPPH radical scavenging activity of each lipid was least for $\mathrm{CF}$ followed by TL, AF and finally MeF (Fig. 2).

Food intake, body weight and body fat

Table 1 shows the average food intake, final body weights, and body fat contents of the mice in each diet group. There were no marked differences in the average food intake between any of the experimental diet groups. At the end of the feeding trial, there were no significant differences in the final body weights between any of the experimental diet groups. The slightly lower values for body fat content in the TL diet groups compared with those of the control and AF diet groups were not significantly different.

Plasma and liver lipids

The plasma and liver T-chol, TG and PL concentrations of mice fed the experimental diets are shown in Fig. 3. Plasma T-chol concentrations were significantly lower in the CF diet group than in the control diet group. There were no significant differences in the plasma TG concentrations between any of the experimental diet groups and the control diet group. The TG concentration was significantly lower in the MeF diet group than in the AF diet group. There were no significant differences between any of the experimental diet groups and the control diet group for plasma PL concentrations.

The content of liver T-chol was not significantly different among the experimental diet groups. TG concentrations of the AF supplemented group were significantly higher that those of the TL and CF diet groups. The liver PL concentrations were significantly lower in mice fed the $\mathrm{CF}$ and MeF diets than those from animals fed the control diet. Further, mice fed the CF diet had significantly lower PL concentrations than those fed the AF diet.

\section{Plasma Glu and TBARS}

The plasma Glu and TBARS concentrations of mice fed the experimental diets are shown in Fig. 4. Glu concentrations were significantly reduced in the TL, CF, AF

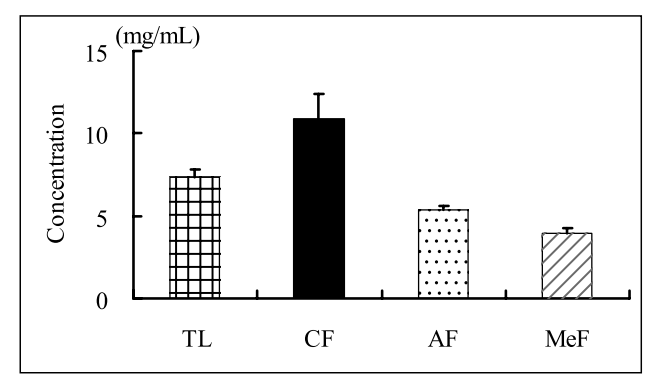

Fig. 2. The concentration of total lipid (TL) and lipid fractions (CF, $\mathrm{AF}$ and $\mathrm{MeF}$ ) necessary for a $50 \%$ inhibition $\left(\mathrm{IC}_{50}\right)$ of $\mathrm{DPPH}$ free radical scavenging. 
Table 1. Average food intake, body weight and body fat content of mice fed the experimental and control diets.

\begin{tabular}{lrrrrr}
\hline \multicolumn{1}{c}{ Groups } & \multicolumn{1}{c}{ Control } & \multicolumn{1}{c}{ TL } & \multicolumn{1}{c}{ CF } & \multicolumn{1}{c}{ AF } & MeF \\
\hline Food intake (g/mouse/d) & $4.56 \pm 0.02$ & $4.58 \pm 0.02$ & $4.56 \pm 0.02$ & $4.57 \pm 0.02$ & $4.53 \pm 0.02$ \\
Body weight (g/mouse) & $47.30 \pm 1.18$ & $44.75 \pm 0.66$ & $46.24 \pm 1.13$ & $48.17 \pm 0.47$ & $45.36 \pm 1.12$ \\
Body fat content (\%) & $14.45 \pm 1.80$ & $11.94 \pm 0.99$ & $13.27 \pm 0.87$ & $15.6 \pm 1.59$ & $13.30 \pm 0.87$ \\
\hline
\end{tabular}

Values are means \pm SE. Means without a common letter differ; $p<0.05$ by the Spjotvoll/Stoline test.

TL, total lipid of tsao-ko; CF, chloroform fraction; AF, acetone fraction; MeF, methanol fraction.
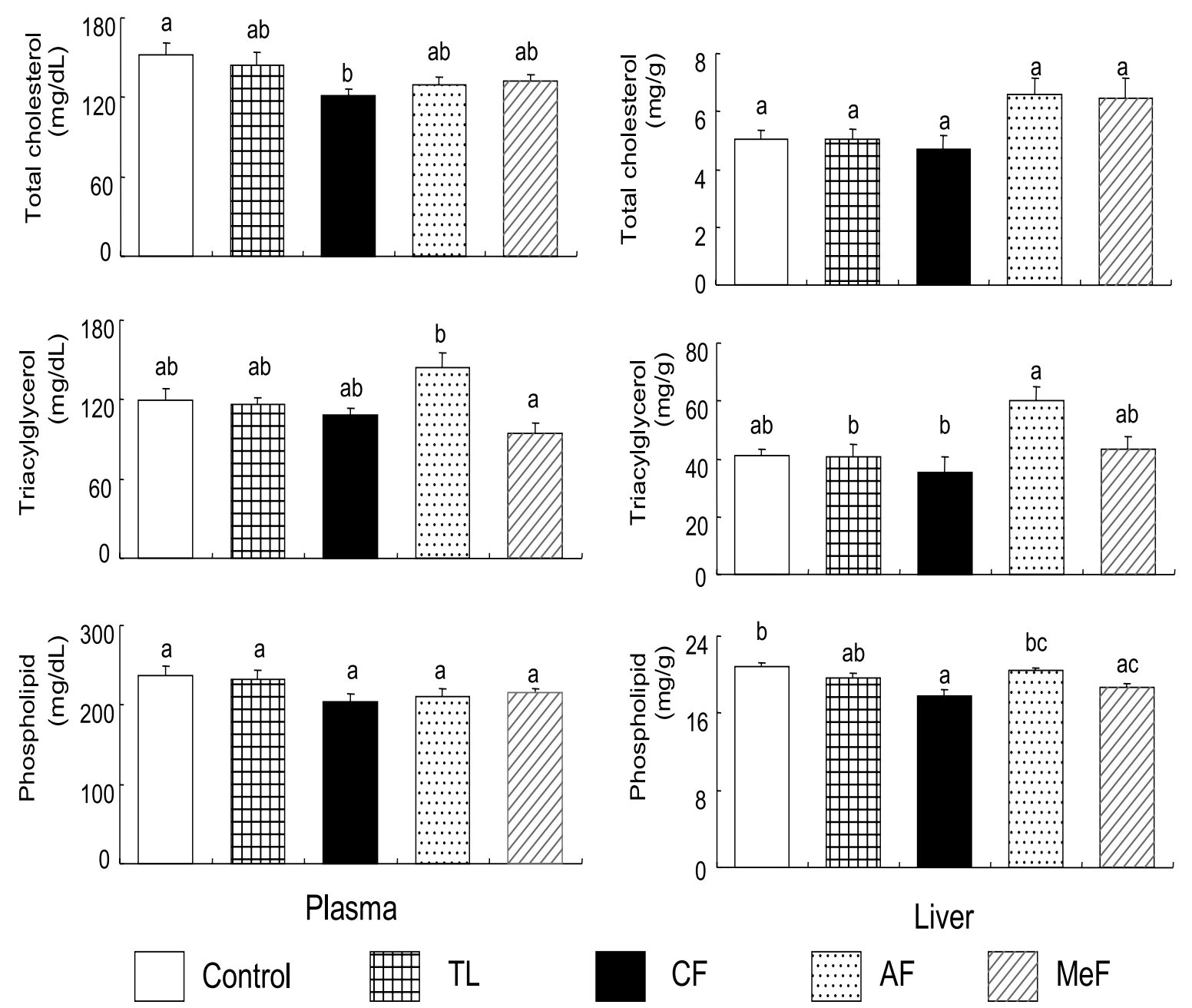

Fig. 3. Total cholesterol, triacylglycerol and phospholipid concentrations of plasma and liver in mice fed experimental and control diets for $90 \mathrm{~d}$ ( $n=8 /$ group). Values are means \pm SE. Means without a common letter differ; $p<0.05$ by the Spjotvoll/Stoline test. TL, total lipid of tsao-ko; CF, chloroform fraction; AF, acetone fraction; MeF, methanol fraction.

and MeF diet groups compared with the control diet group. The average plasma Glu concentration in the MeF diet group was significantly lower than that in either the CF or AF diet groups.

Plasma TBARS concentrations were significantly lower in the $\mathrm{CF}$ and $\mathrm{MeF}$ diet groups than in the control diet group. Additionally, the mean TBARS concentration in the MeF diet group was significantly lower than that of the TL diet group.

\section{DISCUSSION}

The present investigation showed that the potency of different lipid fractions of tsao-ko in inhibiting digestive enzymes varies as do their effects on lipid metabolism in mice. The results support evidence from previous studies that have shown the potential of spice oils to influence various metabolic pathways in ways that may have a positive effect on human health (10-12). A previous study indicated that $\mathrm{AF}$ from spices contains the large amount of glycolipids (15). In the present study, an AF percentage of 48 in the tsao-ko lipids was higher than AF percentages of $7.95,4.61$, and 2.59 in the more common spices clove, red pepper, and nutmeg, respectively (15).

The present study of tsao-ko lipids fractions is consistent with previous reports that have indicated that an 

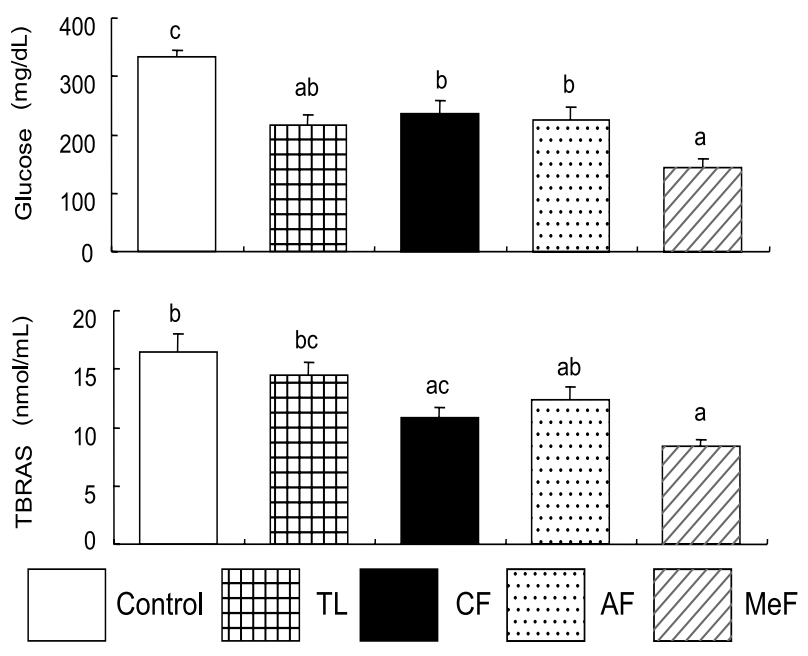

Fig. 4. Plasma glucose and TBARS concentrations of mice fed experimental and control diets for $90 \mathrm{~d}(n=8 /$ group). Values are means \pm SE. Means without a common letter differ; $p<0.05$ by the Spjotvoll/Stoline test. TL, total lipid of tsao-ko; CF, chloroform fraction; AF, acetone fraction; MeF, methanol fraction.

intake of other spices can result in the stimulation or inhibition of the activity of digestive enzymes $(4,5,21)$. For example, the activity of $\alpha$-glucosidase was slightly enhanced by the MeF but strongly inhibited by AF and CF. However, $\alpha$-amylase and lipase activities were both slightly inhibited by all three lipid fractions. Currently it is not known what components of the various fractions are responsible for the inhibitory actions. Martin et al. showed that tsao-ko contains epicatechin and catechin which have inhibitory activity on the digestive enzyme (23). It is possible that various polyphenolic components, such as catechin, previously identified in tsao-ko may be slightly soluble in the lipid fractions and contribute to the inhibition of enzyme activity $(22,23)$. The low emulsion drop size enhances the fat digestion by lipase and lipase inhibitory activity of tea catechin is dependent on the emulsion droplet size $(24,25)$. The decrease in the inhibition of lipase with increasing concentrations of MeF could be due to the variation in emulsive state.

The inhibition of lipase activity contributes to a down-regulation of body weight through the suppression of fat absorption and increases in fat tissue (2628). However, this study did not show a remarkable inhibitory action of total lipid or lipid fractions on lipase or a significant lowering body weight or fat tissue weight. Martin et al. reported that tsao-ko includes epicatechin and catechin, which decrease body weight and fat mass (23). However, these components dissolve almost entirely in water, but barely dissolve in lipids. It is more likely that the components of tsao-ko which suppressed body weight increases $(86.1 \%$ comparison of control) in the previous study (9) are non-fat soluble.

In a previous study we showed that an intake of $1 \%$ tsao-ko decreased TG levels, but not T-chol levels in mice (9). However, the results from this study suggest that fat-soluble components in tsao-ko may influence plasma and liver T-chol and TG levels. The CF diet, which includes triglycerides, significantly reduced plasma T-chol levels compared with the control group. The AF diet, which includes glycolipids, significantly raised plasma TG levels compared with the MeF diet group, which includes phospholipids. An intake of the AF also resulted in higher liver TG levels than those observed following an intake of either the $\mathrm{CF}$ or TL extract.

Plasma Glu levels were decreased in all experimental diet groups compared with control and this may be related to the inhibitory action of TL and the lipid fractions on $\alpha$-glucosidase and $\alpha$-amylase. However, MeF, which resulted in the greatest reduction in plasma Glu, did not inhibit $\alpha$-glucosidase activity and, thus, MeF probably contains other components that influence glucose metabolism in mice.

Although the plasma TBARS concentrations of mice in each lipid fraction diet group were reduced compared with the control diet group, there was little correlation between these reductions and the DPPH radical scavenging activity. For example, the plasma TBARS concentrations of the AF diet group tended to be higher than those of CF diet group but the DPPH radical scavenging activity was much lower in the CF diet group than the AF group. Perhaps the absorption and/or digestion causes the difference between DPPH radical scavenging activity and plasma TBARS level. In contrast, an intake of MeF resulted in a marked DPPH radical scavenging activity and a significant reduction in plasma TBARS concentration. Martin et al. have shown that strong antioxidant components of tsao-ko include catechins and catechol derivatives (23) and it is possible that the reduction in plasma TBARS in mice fed the $\mathrm{MeF}$ is associated with these components. Although these observations strongly support the concept that the antioxidant components of tsao-ko may be fat-soluble polar components, an intake of TL did not significantly reduce the level of plasma TBARS.

The purpose of this study was to clarify the fraction in tsao-ko which suppressed body weight, modified the plasma TG, TBARS, and Glu concentrations as seen in our previous study of tsao-ko. The results showed that the extracted lipid fractions of tsao-ko inhibited digestive enzymes and oxidant activity, either increased or decreased plasma TG, and decreased plasma TBARS and Glu concentrations. It has been shown that polar solvent extracts of various herbs have strong antioxidant activity (29). In the present study the fractions of tsao-ko that markedly influenced plasma Glu and TBARS levels and antioxidant activity were in the MeF, which contains the fat-soluble polar components. The lowering effects of tsao-ko on plasma and liver TG levels and body weight do not appear to reside in the lipid components.

\section{REFERENCES}

1) Cadby P. 2004. Novel estimates of the exposure to flavouring substances. Toxicol Lett 149: 215-222.

2) Lai PK, Roy J. 2004. Antimicrobial and chemopreven- 
tive properties of herbs and spices. Curr Med Chem 11: 1451-1460.

3) Hirasa K, Takemasa M. 1998. The patterning theory of spice use. In: Spice Science and Technology (Hirasa K, Takemasa M, eds), p 85-140. Marcel Dekker, Hong Kong.

4) Platel K, Srinivasan K. 2004. Digestive stimulant action of spices: a myth or reality? Indian J Med Res 119: 167179.

5) Srinivasan K. 2005. Spices as influencers of body metabolism: an overview of three decades of research. Food Res Int 38: 77-86.

6) Hirasa K, Takemasa M. 1998. Physiological effects of spice components. In: Spice Science and Technology (Hirasa K, Takemasa M, eds), p 141-162. Marcel Dekker, Hong Kong.

7) Rahman K, Lowe GM. 2006. Garlic and cardiovascular disease: a critical review. J Nutr 136: 736S-740S.

8) Hirasa K, Takemasa M. 1998. In: Spice Science and Technology (Hirasa K, Takemasa M, eds), p 163-200. Marcel Dekker, Hong Kong.

9) Yu L, Shirai N, Suzuki H. 2007. Effects of some Chinese spices on plasma lipids, lipid peroxides, and glucose, and liver lipids in mice. Food Sci Technol Res 13: 155-161.

10) Ebihara T, Ebihara S, Maruyama M, Kobayashi M, Itou A, Arai H, Sasaki H. 2006. A randomized trial of olfactory stimulation using black pepper oil in older people with swallowing dysfunction. J Am Geriatr Soc 54: 1401-1406.

11) Bozin B, Mimica-Dukic N, Simin N, Anackov G. 2006. Characterization of the volatile composition of essential oils of some lamiaceae spices and the antimicrobial and antioxidant activities of the entire oils. J Agric Food Chem 54: 1822-1828.

12) Verma SK, Rajeevan V, Jain P, Bordia A. 2005. Effect of garlic (Allium sativum) oil on exercise tolerance in patients with coronary artery disease. Indian J Physiol Pharmacol 49: 115-118.

13) Liu HG, Xu LH. 2007. Garlic oil prevents tributyltininduced oxidative damage in vivo and in vitro. $J$ Food Prot 70: $716-721$.

14) Mukherjee M, Das AS, Mitra S, Mitra C. 2004. Prevention of bone loss by oil extract of garlic (Allium sativum Linn.) in an ovariectomized rat model of osteoporosis. Phytother Res 18: 389-394.

15) Suzuki H, Park WK, Lim SY. 2000. Analyses of glycolipids in clove, red pepper, and nutmeg by high-perfor- mance liquid chromatography. J Food Sci 65: 931-933.

16) Bligh EG, Dyer WJ. 1959. A rapid method of total lipid extraction and purification. Can J Biochem Physiol 37: 911-917.

17) Tadera K, Minami Y, Takamatsu K, Matsuoka T. 2006. Inhibition of alpha-glucosidase and alpha-amylase by flavonoids. J Nutr Sci Vitaminol 52: 149-153.

18) Han LK, Xu BJ, Kimura Y, Zheng Y, Okuda H. 2000. Platycodi radix affects lipid metabolism in mice with high fat diet-induced obesity. J Nutr 130: 2760-2764.

19) Bloiss HS. 1958. Antioxidant determinations by the use of stable free radical. Nature 181: 1199-1200.

20) Yagi K. 1976. A simple fluorometric assay for lipoperoxide in blood plasma. Biochem Med 15: 212-216.

21) Ramakrishna Rao R, Platel K, Srinivasan K. 2003. In vitro influence of spices and spice-active principles on digestive enzymes of rat pancreas and small intestine. Nahrung 47: 408-412.

22) Moon SS, Lee JY, Cho SC. 2004. Isotsaokin, an antifungal agent from Amonum tsao-ko. J Nat Prod 67: 889891.

23) Martin TS, Kikuzaki K, Hisamoto M, Nakatani N. 2000. Constituents of Amonum tsao-ko and their radical scavenging and antioxidant activities. J Am Oil Chem Soc 77: 667-673.

24) Shishikura Y, Khokhar S, Murray BS. 2006. Effects of tea polyphenols on emulsification of olive oil in a small intestine model system. J Agric Food Chem 54: 19061913.

25) Armand M, Pasquier B, André M, Borel P, Senft, M, Peyrot J, Salducci J, Portugal H, Jaussan V, Lairon D. 1999. Digestion and absorption of 2 fat emulsions with different droplet sizes in the human digestive tract. Am J Clin Nutr 70: 1096-1106.

26) Koo SI, Noh SK. 2007. Green tea as inhibitor of the intestinal absorption of lipids: potential mechanism for its lipid-lowering effect. J Nutr Biochem 18: 179-183.

27) Han LK, Zheng YN, Xu BJ, Okuda H, Kimura Y. 2002. Saponins from platycodi radix ameliorate high fat dietinduced obesity in mice. J Nutr 132: 2241-2245.

28) Karu N, Reifen R, Kerem Z. 2007. Weight gain reduction in mice fed Panax ginseng saponin, a pancreatic lipase inhibitor. J Agric Food Chem 55: 2824-2828.

29) Al-Dabbas MM, Kitahara K, Suganuma T, Hashimoto F, Tadera K. 2006. Antioxidant and alpha-amylase inhibitory compounds from aerial parts of Varthemia iphionoides Boiss. Biosci Biotechnol Biochem 70: 2178-2184. 